УДК $550.83+552.5+553.98$

\title{
ВТОРИЧНЫЕ КАРБОНАТЫ ЮРСКИХ ПЕСЧАНЫХ ОТЛОЖЕНИЙ КАК ПОКАЗАТЕЛИ ПРОДУКТИВНОСТИ ПАЛЕОЗОЯ
}

\author{
Мельник Игорь Анатольевич1, \\ migranis@mail.ru
}

\author{
Недоливко Наталья Михайловна', \\ nedolivko@tpu.ru
}

\author{
Зимина Светлана Валерьевна', \\ ziminasv@tpu.ru \\ 1 Национальный исследовательский Томский политехнический университет, \\ Россия, 634050, г. Томск, пр. Ленина, 30.
}

Работа основана на концепции глубинного генезиса флюидов с последующей субвертикальной миграцией (снизу вверх) по
проницаемым зонам и разгрузкой в вышележащих коллекторах. Причем в зонах разгрузки и на путях миграции флюидов про-
исходят геохимические преобразования аллотигенных минералов. Интенсивности процессов вторичного, наложено-
эпигенетического образования минералов зависят от физико-химических свойств жидкости и скорости её течения.
Целью статьи является иллюстрация связи интенсивности процессов вторичной карбонатизации юрских песчаных отло-
жений с характером насыщения палеозойских пород.
Методы. Интенсивность вторичной карбонатизации определялась по инновационной технологии статистической интер-
претации материалов геофизических исследований скважин. Проводились сопоставления полученных статистических ин-
тенсивностей с результатами литолого-петрограсических, минералогических исследований керна на предмет содержания
карбонатов и с результатами испытаний палеозойских коллекторов. Актуальность работы обусловлена появившейся возможностью с высокой вероятностью выявлять зоны расположения нефртегазовых залежей в фундаменте по результатам статистической интерпретации данных геофизических исследований скважин юрских отложений, используя материалы старого фонда.

Объектом исследования явились песчаные пласты юрского возраста Герасимовского месторождения (Томская область), а также карбонатные минералы, расположенные в песчаной породе.

Выводы. Усреднённая интенсивность процесса вторичной карбонатизации в юрских песчаных отложениях является индикатором характера насыщения палеозойских пластов. С ростом интенсивности карбонатизации юрских пластов увеличивается вероятность обнаружения нефтенасыщенных залежей в фундаменте. С точки зрения выявления продуктивных залежей палеозоя наиболее информативным карбонатным минералом в юрских пластах является аутигенный сидерит.

\section{Ключевые слова:}

Геофизические исследования скважин, нефртегазоносность палеозоя, вторичные карбонаты, глубинная миграция фрлюидов, Герасимовское месторождение.

\section{Введение}

В настоящее время прирост запасов углеводородного сырья на Юго-Востоке Западно-Сибирской плиты в большей степени связывают с палеозойскими отложениями. В 60-80 гг. прошлого века бурение и сопутствующие геофизические исследования скважин (ГИС), как правило, проводили до палеозойского горизонта, вследствие доминирующего представления геологов о перспективности только юрских коллекторов. Поэтому современный поиск продуктивных залежей в фундаменте, даже на наиболее изученной западной территории Томской области, осуществляется по результатам бурения. Что экономически не всегда целесообразно.

В свою очередь, многолетние изучения процессов наложенного эпигенеза в терригенных отложениях убедительно показали, что вторичные литолого- минералогические изменения пород обусловлены поступлением глубинных флюидов [1-14]. Соответственно, в зависимости от физико-химических свойств флюидов, внедряемых в верхние горизонты пород (по субвертикальным ослабленным зонам), меняется как состав аллотигенных минералов, слагающих данные породы, так и состав новообразованных аутигенных минералов. По определенному качеству и интенсивности вторичных изменений можно судить о характере насыщения нижележащих отложений [15-17].

Целью данной работы является иллюстрация связи интенсивности процесса вторичной карбонатизации юрских песчаных отложений с характером насыщения палеозойских пород. Интенсивность вторичной карбонатизации определялась по инновационной технологии статистической интерпретации материалов ГИС [18]. Проводились сопоставления полученных статистических интенсивностей с результатами литолого-петрографических, минералогических исследований керна и с результатами испытаний палеозойских коллекторов.

Объектом исследований явились песчаные пласты сероцветной формации юрского возраста (ааленоксфорд) Герасимовского месторождения (Томская область), приуроченного к структуре первого порядка-Северо-Межовской мегамоноклинали и второго порядка - Чузикско-Чижапской мезоседловины. 
Актуальность этой работы обусловлена появившейся возможностью с высокой вероятностью выявлять зоны расположения нефтегазовых залежей в фундаменте по результатам статистической интерпретации данных ГИС юрских отложений, используя материалы старого фонда.

\section{Методы и анализ результатов исследований}

Корректность и валидность метода статистической интерпретации материалов ГИС раннее были подтверждены результатами лабораторных исследований керна $[16,18]$. В основе данной технологии лежит следующий принцип - если эпигенетический процесс является причиной одновременного изменения двух (и более) исследуемых характеристик породы, то статистические параметры корреляционных зависимостей между выборками данных характеристик будут отражать влияния интенсивностей процессов на породу. К таким параметрам относят коэффициент аппроксимации $\left(R^{2}\right)$ и интервальный параметр $(Y)$. Произведение статистических параметров $i=Y R^{2}$ назовем статистической интенсивностью вторичных процес$c o b$, выражающей как качественную $\left(R^{2}\right)$, так и количественную $(Y)$ меры статистических регрессионных связей [18].

Например, по данным ГИС, карбонатные интервалы выделяются повышением показаний стационарных нейтронных методов (ННКт, НГК) и одновременным понижением показаний гамма-каротажа (ГК). Это обусловлено понижением водородосодержания и радиоактивных элементов (изотопов калия, тория и радия) в карбонатах относительно полиминеральных песчаных пород. Относительно аллотигенных карбонатов вторичные карбонаты отличаются повышенным содержанием редкоземельных элементов, которые имеют высокое микроскопическое сечение поглощения тепловых нейтронов [3, 19]. Поэтому положительная регрессия между выборками макроскопического сечения поглощения тепловых нейтронов и карбонатностью породы будет отражать вторичную, аутигенную карбонатность в исследуемом карбонатно-песчаном интервале. А статистическая интенсивность вторичной карбонатности пропорционально коррелирует с её содержанием.

Разработанная инновационная технология определения интенсивности вторичных геохимических процессов по материалам промысловой геофизики основана на вычислении макроскопического сечения поглощения тепловых нейтронов по материалам стандартного комплекса ГИС (НГК, либо ННКт и ГК) [18] Что позволяет определять интенсивность вторичной карбонатизации.

В качестве объекта исследований выбраны песчаные отложения юры в 12-ти скважинах Герасимовского месторождения, в которых были проведены испытания перспективных палеозойских отложений. Статистическая интерпретация по каждому песчаному интервалу позволяет определить величину интенсивности вторичного процесса исследуемого интервала. Была проведена статистическая интерпретация данных ГИС в 34-х песчаных интервалах юры 6-ти скважин («перспективных»), где в палеозое обнаружены нефтенасыщенные пласты, и в 49-ти песчаных пластах юры, в скважинах которых в палеозойских отложениях испытания показали насыщение «вода», либо «сухо», т. е. «бесперспективных» (табл. 1).

Таблица 1. Результаты вычисления статистической интенсивности вторичной карбонатизации u петрографического анализа керна на предмет содержания карбонатных минералов, усреднённых по юрским песчаным пластам Герасимовского месторождения

Table 1. Results of calculating the statistical intensity of secondary carbonation and petrographic analysis of the core for the content of carbonate minerals averaged over the Jurassic sand layers of the Gerasimov Deposit

\begin{tabular}{|c|c|c|c|c|}
\hline $\begin{array}{c}\text { № скважины } \\
\text { Well no. }\end{array}$ & 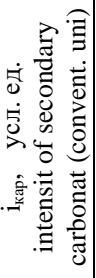 & 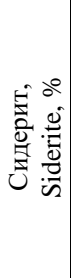 & 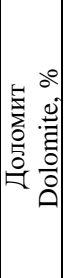 & 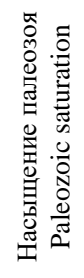 \\
\hline 1 & 0,07 & 55 & 26 & \multirow{6}{*}{$\begin{array}{c}\text { нефть } \\
\text { oil }\end{array}$} \\
\hline 5 & 0,20 & 75 & 20 & \\
\hline 7 & 0,23 & 78 & 4,0 & \\
\hline 8 & 0,17 & 75 & 19 & \\
\hline 11 & 0,15 & 49 & 45 & \\
\hline 12 & 0,05 & 63 & 76 & \\
\hline $\begin{array}{l}\text { Средние величины } \\
\text { для «перспективных» скважин } \\
\text { Average values for «perspective» } \\
\text { wells } \\
\end{array}$ & 0,145 & 66 & 32 & \\
\hline 2 & 0 & 48 & 0,5 & $\begin{array}{l}\text { вода } \\
\text { water }\end{array}$ \\
\hline 3 & 0,07 & 70 & 12 & $\begin{array}{c}\text { вода } \\
\text { water }\end{array}$ \\
\hline 10 & 0,09 & 77 & 26 & $\begin{array}{c}\text { cyxo } \\
\text { stiffly }\end{array}$ \\
\hline 14 & 0,10 & 50 & 35 & $\begin{array}{c}\text { вода } \\
\text { water }\end{array}$ \\
\hline 15 & 0,15 & 57 & 40 & $\begin{array}{c}\text { cyxo } \\
\text { stiffly }\end{array}$ \\
\hline 16 & 0,03 & 53 & 31 & $\begin{array}{l}\text { cyxo } \\
\text { stiffly }\end{array}$ \\
\hline $\begin{array}{l}\text { Средние величины } \\
\text { для «бесперспективных» скважин } \\
\text { Average values for «unpromising» } \\
\text { wells }\end{array}$ & 0,07 & 59 & 24 & \\
\hline
\end{tabular}

В табл. 1 показаны средние значения (по скважине) интенсивности вторичной карбонатизации для всего юрского комплекса песчаных пород, т. е. усреднение по количеству интервалов проводилось от 3 до 11 выборочных значений. Лабораторный анализ керна на предмет усреднённого содержания доломита и сидерита от количества зерен в аутигенной части тяжелой фракции проводился по всему юрскому разрезу. В последнем столбце табл. 1 даны результаты испытания пластов палеозойского фундамента, в результате чего выделились две группы скважин: «перспективная» и «бесперспективная». 


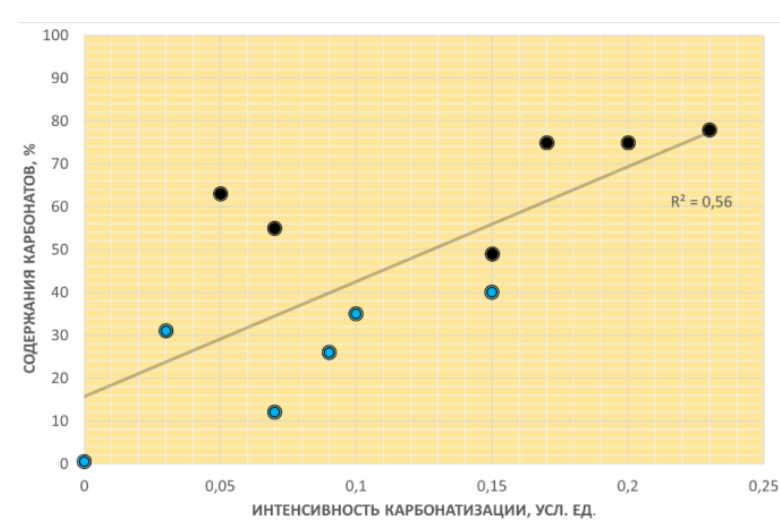

Pис. 1. Сопоставление содержаний карбонатов, определенных по керну с интенсивностью карбонатизации, вычисленной по материалам ГИС, усреднённых по юрским песчаным породам (голубым ияветом обозначены данные «бесперспективныху скважин)

Fig. 1. Comparison of the contents of carbonates determined from the core with the intensity of carbonation calculated from GIS materials averaged over Jurassic sand rocks (blue color indicates data of «unpromising» wells)

Сопоставления содержаний вторичных карбонатов, определенных лабораторным методом с интенсивностью вторичной карбонатизации, вычисленной по данным ГИС, показали положительную регрессию с коэффициентом корреляции 0,75 (рис. 1). Причем для группы «перспективных» скважин интенсивность коррелирует с сидеритом, а для группы «бесперспективных» - с доломитом.

Результаты анализа данных табл. 1 позволяют утверждать, что усреднённая (по юрским песчаникам) интенсивность вторичной карбонатизации является индикатором присутствия нефти в палеозойских отложениях. Средняя величина интенсивности по «перспективным» скважинам на территории нефтесодержащих отложений палеозоя в 2 раза больше величины данной интенсивности «бесперспективной» зоны. Однофакторный дисперсионный анализ двух выборок интенсивностей вторичной карбонатизации «перспективных» и «бесперспективных» скважин определил фактор Фишера $\mathrm{F}=5,5>\mathrm{F}_{\mathrm{rp}}=4,7$, что указывает на их существенное статистическое различие. Граничное значение интенсивности $i(2 p)_{\text {кар }}=0,15$ усл. ед. разделяет интервалы на нефтенасыщенную и «малоперспективную» зоны. Соответственно, пятьдесят процентов «перспективных» скважин (№ $5,7,8)$ попадают в область нефтенасыщенных палеозойских отложений.

\section{Обобщение полученных результатов}

В [16] были показаны результаты исследований параметров мультипликативных интенсивностей вторичных процессов каолинитизации, карбонатизации и пиритизации, усредненных по меловым пластам в присутствии и при отсутствии нефтенасыщенных залежей в юре. Если мультипликативный параметр (для меловых отложений Томской области) больше определенной граничной величины, то с вероятностью более 0,9 в юрском горизонте присутствует нефть.

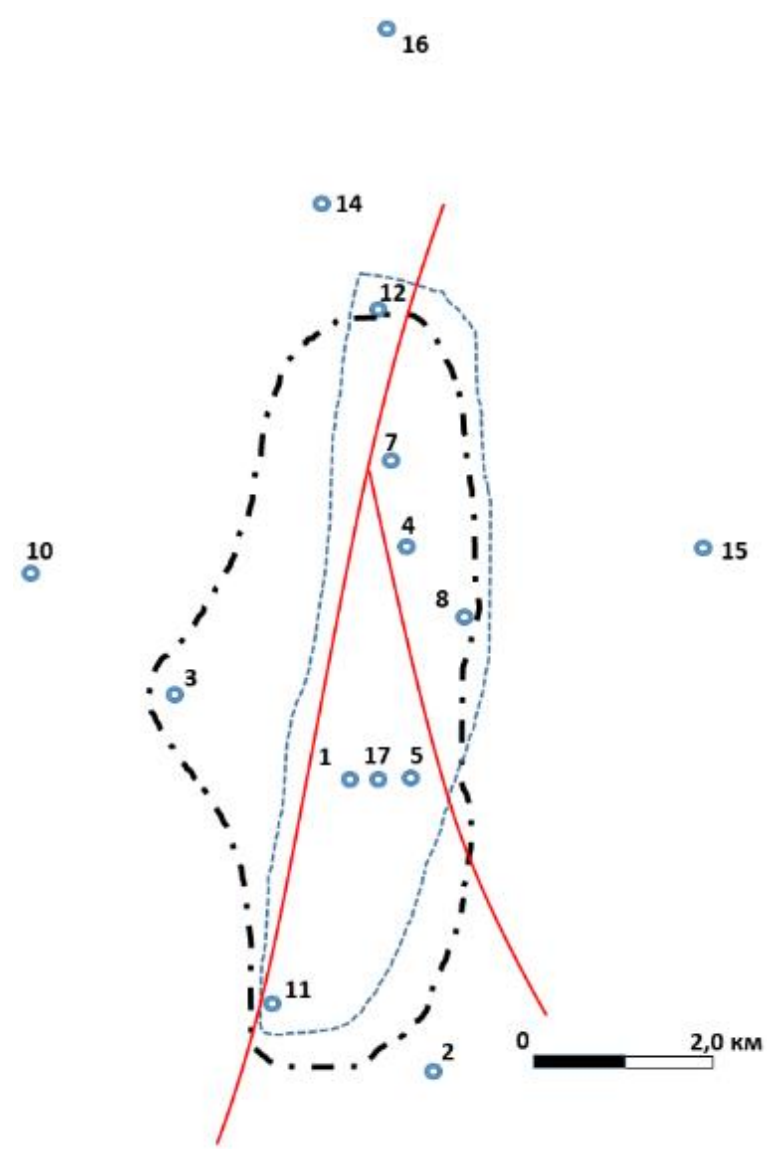

Рис. 2. Схема расположения исследуемых скважин Герасимовского месторождения, где -...- контур антиклинального выступа фундамента, ............ - контур перспективной области нефтегазонасыщения в палеозое, — - разлом по фундаменту (В.С. Сурков, 1981 [20])

Fig. 2. Scheme of location of the investigated wells in Gerasimovskoe field, where -...-- the outline of the anticlinal bulge of the foundation, ...........- the outline of promising areas of oil saturation in the Paleozoic, - the rift in the foundation (V.S. Surkov, 1981 [20])

Полученные результаты сопоставления интенсивностей вторичной карбонатизации песчаных пластов юры Герасимовского месторождения с результатами испытания пластов палеозоя полностью подтвердили концепцию влияния флюидов нижележащих залежей на интенсивности вторичных процессов в породах вышележащих пластов. Выделяется следующая закономерность - все «перспективные» скважины расположились на территории антиклинального выступа палеозойского фундамента в песчаниках пласта $Ю_{9}$ (рис. 2). Контур «перспективной» зоны находится в пределах данного выступа, и, что характерно, «перспективные» скважины расположены возле $\lambda$-образного разлома по фундаменту [20].

Обрамляющие песчаное тело с востока алевритоглинистые отложения с прослоями песчаников и углей формировались в болотно-водораздельных фациях. По составу песчаники граувакково-кварцполевошпатовые с обломками кремнистых пород, гранитоидов, сланцев и эффузивов. Первичный це- 
мент в них представлен смесью тонкодисперсных глинистых минералов, вторичный, согласно данным рентгенофазового анализа, - каолинитом, хлоритом, пиритом, карбонатами (сидеритом, доломитом и кальцитом). Генетическая связь карбонатного аутигенеза с палеозойскими залежами может быть подтверждена следующим.

Таблица 2. Средние содержания вторичных карбонатов в юрских отложениях Герасимовского месторождения, определенные по результатам микрозондового анализа керна

Table 2. Average content of secondary carbonates in Jurassic deposits of Gerasimovskoe field, determined by the results of microprobe core analysis

\begin{tabular}{|c|c|c|c|c|}
\hline $\mathrm{FeCO}_{3}$ & $\mathrm{MgCO}_{3}$ & $\mathrm{CaCO}_{3}$ & $\mathrm{MnCO}_{3}$ & $\begin{array}{c}\text { Насыщение палеозоя } \\
\text { Saturation of the Paleozoic }\end{array}$ \\
\hline \multicolumn{5}{|c|}{$\%$} \\
\hline 35,6 & 36,7 & 26,5 & 1,2 & Нефть/Oil \\
\hline 13,4 & 19,3 & 65,3 & 1,9 & Вода/Water \\
\hline
\end{tabular}

По результатам микрозондового анализа состав вторичных карбонатов в толщах, перекрывающих палеозойскую залежь, и толщах, перекрывающих водонасыщенные породы, различен (табл. 2). Карбонаты надпродуктивного комплекса в «перспективных» скважинах более железистые и магнезиальные, а над «бесперспективными» районами более кальциевые и марганцовистые. С геохимических позиций это объясняется различной подвижностью катионов железа, магния, кальция и марганца, мигрирующих в перекрывающие залежь отложения по разломам, оперяющим его трещинам, ослабленным трещиноватостью зонам. Источником катионов служили, с одной

\section{СПИСОК ЛИТЕРАТУРЫ}

1. Природный тектонический насос углеводородов и вторичная доломитизация - порождение тектоно-гидротермальной активности рифтогенного осадочного бассейна / А.Д. Коробов, Л.А. Коробова, Е.Ф. Ахлестина, А.Т. Колотухин, В.М. Мухин // Известия Саратовского университета. Серия «Науки о Земле». - 2015. - Т. 15. - Вып. 3. - С. 46-52.

2. Предтеченская Е.А., Шиганова О.В., Фомичев А.С. Катагенетические и гидрохимические аномалии в нижнесреднеюрских нефтегазоносных отложениях Западной Сибири как индикаторы флюидодинамических процессов в зонах дизъюнктивных нарушений // Литосфера. - 2009. - № 6. - С. 54-65.

3. Карнюшина Е.Е. Основные причины возникновения зон карбонатной цементации в толщах нефтегазоносных бассейнов // Вестник Московского университета. Серия 4. Геология. 2012. - № 5. - C. 47-49.

4. Баженов В.А., Недоливко Н.М., Казарбин В.В. Рассеянное оруденение в осадочных породах Западно-Сибирской плиты // Геология и геофизика. - 1993. - Т. 34. - № 3. - С. 132-136.

5. Геохимические критерии выявления коллекторов и прогноза их нефтегазоносности в терригенных отложениях ПурТазовской нефтегазоносной области / Е.Р. Исаева, В.Г. Ворошилов, Т.Ф. Тимкин, M. Ziaii // Известия Томского политехнического университета. Инжиниринг георесурсов. - 2018. T. 329. - № 4. - C. 132-141.

6. Lasaga A.C. Chemical kinetics of water-rock interactions // J. Geophys. Res. - 1984. - V. 89. - P. 4009-4025.

7. Duan S., Wojtanowicz A.K. Theoretical and experimental investigation of water in oil transverse dispersion in porous media // SPE Annual Technical Conference and Exhibition. Denver, Colorado, USA, 2008. - P. 1376-1401. стороны, глубинные недра, с другой - щелочные минерализованные поровые воды и минеральная матрица песчаных пород, сквозь которые осуществлялась флюидомиграция. Обладая высокой миграционной способностью в кислых водах (ювенильных и генерированных мигрирующими углеводородами), в щелочной обстановке катионы теряют миграционную способность и формируют карбонаты сложного состава. Менее подвижные железо и магний концентрируются непосредственно над залежью в миграционном следе, более подвижные - кальций и марганец - перемещаются от залежи на большие расстояния.

\section{Заключение}

На основании проведенных исследований, в рамках концепции субвертикальной миграции глубинных флюидов, можно сделать следующие выводы:

1. Усреднённая интенсивность процесса вторичной карбонатизации в юрских песчаных отложениях является индикатором характера насыщения палеозойских пластов.

2. С ростом интенсивности карбонатизации юрских пластов увеличивается вероятность обнаружения нефтенасыщенных залежей в фундаменте.

3. С точки зрения выявления продуктивных залежей палеозоя наиболее информативным карбонатным минералом в юрских пластах является аутигенный сидерит.

Таким образом, по результатам статистической интерпретации данных ГИС юрских отложений, используя материалы старого фонда, с высокой долей вероятности можно выявлять зоны расположения продуктивных нефтегазовых залежей в фундаменте.

8. Alteration of crude oil by waters and bacteria; evidence from geochemical and isotope studies / N.J.L. Bailey, H.R. Krouse, C.R. Evans, M.A. Rogers // AAPG Bull. - 1973. - V. 57. - P. 1276-1290.

9. Velbel M.A. Influence of surface area, surface characteristics, and solution composition on feldspar weathering rates // Symposium Series: Geochemical Processes at Mineral Surfaces. - Chicago, Illinois, 1986. - № 323. - P. 614-634.

10. Worden R.H., Burley S.D. Sandstone diagenesis. Recent and Ancient. - United States of America: Blackwell Publishing company, 2003. $-647 \mathrm{p}$.

11. Worden R.H., Morad S. Clay mineral cements in sandstones. United States of America: Blackwell Publ. company, 2003. - 503 p.

12. Bjorkum P.A., Gielsvik N. An isochemical model for formation of authigenic kaolinite, K-feldspar and illite in sediments // J. Sedim Petrol. - 1988. - V. 58. - P. 506-511.

13. Shengkai D., Wojtanowicz A.K. Hydrodynamic transition zone at OWC in non-Darcy flow // The second International Energy 2030 conference. - Abu Dhabi U.A.E., 2008. - P. 84-86.

14. Helgeson H.C., Owens C.E., Shock E.L. Petroleum, oil field waters, and authigenic mineral assemblages: are they in metastable equilibrium in hydrocarbon reservoirs? // Geochimica et Cosmochimica Acta, Abstr. - 1993. - V. 57. - P. 3295-3339.

15. Мельник И.А. Интенсивности процессов наложенного эпигенеза как индикаторы нефтенасыщенности песчаных коллекторов // Известия Томского политехнического университета. Инжиниринг георесурсов. - 2019. - Т. 330. - № 6. - С. 90-97.

16. Мельник И. А., Шарф И.В. Повышение ценности информации при интерпретации стандартных материалов геофизических исследований скважин // Научно-технический журнал «Нефтегазовое дело». - 2018. - T. 16. - № 3. - C. 11-21. URL: http://ngdelo.ru/files/ngdelo/2018/3/ngdelo-3-2018-p11-21.pdf (дата обращения 10.09.2019). 
17. Мельник И. А., Шарф И.В., Иванова М.П. Статистический параметр двойного электрического слоя как индикатор нефтенасыщенности нижнесреднеюрских отложений Томской области // Нефтяное хозяйство. - 2018. - № 10. - С. 24-26.

18. Мельник И.А. Определение интенсивности геохимических процессов по материалам геофизических исследований скважин. - Новосибирск: Сибирский научно-исследовательский институт геологии, геофизики и минерального сырья, 2016. $146 \mathrm{c}$.
19. Редкоземельные элементы в баженовской свите ЗападноСибирского осадочного бассейна / Ю.Н. Занин, А.Г. Замирайлова, В.Г. Эдер, В.О. Красавчиков // Литосфера. - 2011. № 6. - C. 38-54.

20. Сурков В.С., Жеро О.Г. Фундамент и развитие чехла ЗападноСибирской плиты. - М.: Недра, 1981. - 143 с.

Поступила 12.09.2019 2.

\section{Информация об авторах}

Мельник И.А., доктор геолого-минералогических наук, профессор, и.о. заведующего кафедрой - руководителя отделения нефтегазового дела Инженерной школы природных ресурсов Национального исследовательского Томского политехнического университета.

Недоливко Н.М., кандидат геолого-минералогических наук, доцент отделения геологии Инженерной школы природных ресурсов Национального исследовательского Томского политехнического университета.

Зимина $\boldsymbol{C . B .}$, кандидат геолого-минералогических наук, доцент отделения геологии Инженерной школы природных ресурсов Национального исследовательского Томского политехнического университета. 


\title{
UDC $550.83+552.5+553.98$
}

\section{SECONDARY CARBONATES OF JURASSIC SAND DEPOSITS AS INDICATORS OF THE PALEOZOIC PRODUCTIVITY}

\author{
Igor A. Melnik' \\ migranis@mail.ru
}

\author{
Natalya M. Nedolivko1, \\ nedolivko@tpu.ru
}

\author{
Svetlana V. Zimina1, \\ ziminasv@tpu.ru \\ ${ }_{1}$ National Research Tomsk Polytechnic University, \\ 30, Lenin avenue, Tomsk, 634050, Russia.
}

This work is based on the concept of deep genesis of fluids, followed by subvertical migration (from the bottom up) through permeable zones and unloading in overlying reservoirs. Moreover, geochemical transformations of allogenic minerals occur in the discharge zones and on the fluid migration routes. The intensities of secondary, superimposed-epigenetic formation of minerals depend on liquid physical and chemical properties and its flow velocity.

The aim of the article is to show the relation between the intensity of secondary carbonation of Jurassic sand deposits and the nature of saturation of the Paleozoic rocks.

The intensity of secondary carbonation was determined using advanced technology of statistical logging interpretation. The results of the intensities were compared with the results of lithologic-petrographic, mineralogical studies of the core-samples and with the results of the Paleozoic collectors tests.

The relevance of this research is associated with the opportunity to identify the location of oil and gas deposits in the bottom of layer based on the results of statistical interpretation of production logging data in Jurassic sediments, using the materials of the old Fund.

The object of the research is the Jurassic sand layers at the Gerasimovskoe field (Tomsk Region). When the intensity of Jurassic layer carbonation grows the probability of detection of oil-saturated deposits increases too. From the perspective of identifying the Paleozoic productive deposits, the authigene siderite is the most informative carbon-bearing mineral in the Jurassic sediments.

\section{Key words:}

Well logging, the Paleozoic oil-and-gas content, secondary carbonates, fluid depth migration, Gerasimovskoe field.

\section{REFERENCES}

1. Korobov A.D., Korobova L.A., Akhlestina E.F., Kolotukhin A.T., Mukhin V.M. Natural tectonic pump for hydrocarbons and secondary dolomitization - the result of hydrothermal processes in rift-induced sedimentary basin. Izvestiya of Saratov University. Earth science, 2015, vol. 15, Iss. 3, pp. 46-52. In Rus.

2. Predtechenskaya E.A., Shiganova O.V., Fomichev A.S Catagenetic and hydrochemical anormalies in lower-Middle Jurassic oil-bearing deposits of Western Siberia, as an indicator of fluid dynamics in disjunction zones. Lithosphere, 2009, no. 6, pp. 54-65. In Rus.

3. Karnyushina E.E. Main reasons of carbonization area occurrence in layers of oil and gas bearing basins. Moscow University Bulletin. Series 4. Geology, 2012, no. 5, pp. 47-49. In Rus.

4. Bazhenov V.A., Nedolivko N.M., Kazarbin V.V. Scattered mineralization in sedimentaries of Western Siberian plate. Geology and geophysics, 1993, vol. 34, no. 3, pp. 132-136. In Rus.

5. Isaeva E.R., Voroshilov V.G., Timkin T.F., Mansour Ziaii. Geochemical criteria to identify reservoirs and to forecast their oil and gas content in terrigenous deposits in Pur-Tazovskoy oilbearing field. Bulletin of the Tomsk Polytechnic University. Geo Assets Engineering, 2018, vol. 329, no. 4, pp. 132-141. In Rus.

6. Lasaga A.C. Chemical kinetics of water-rock interactions. $J$. Geophys. Res., 1984, vol. 89, pp. 4009-4025.

7. Duan S., Wojtanowicz A.K. Theoretical and experimental investigation of water in oil transverse dispersion in porous media. SPE Annual Technical Conference and Exhibition. Denver, Colorado, USA, 2008. pp. 1376-1401.

8. Bailey N.J.L., Krouse H.R., Evans C.R., Rogers M.A. Alteration of crude oil by waters and bacteria; evidence from geochemical and isotope studies. AAPG Bull., 1973, vol. 57, pp. 1276-1290.

9. Velbel M.A. Influence of surface area, surface characteristics, and solution composition on feldspar weathering rates. Symposium
Series: Geochemical Processes at Mineral Surfaces. Chicago, Illinois, 1986. No. 323, pp. 614-634.

10. Worden R.H., Burley S.D. Sandstone diagenesis. Recent and Ancient. United States of America, Blackwell Publishing company, 2003. $647 \mathrm{p}$.

11. Worden R.H., Morad S. Clay mineral cements in sandstones. United States of America, Blackwell Publ. company, 2003. 503 p.

12. Bjorkum P.A., Gielsvik N. An isochemical model for formation of authigenic kaolinite, K-feldspar and illite in sediments. J. Sedim Petrol., 1988, vol. 58, pp. 506-511.

13. Shengkai D., Wojtanowicz A.K. Hydrodynamic transition zone at OWC in non-Darcy flow. The second International Energy 2030 conference. Abu Dhabi U.A.E., 2008. pp. 84-86.

14. Helgeson H.C., Owens C.E., Shock E.L. Petroleum, oil field waters, and authigenic mineral assemblages: are they in metastable equilibrium in hydrocarbon reservoirs? Geochimica et Cosmochimica Acta, Abstr., 1993, vol. 57, pp. 3295-3339.

15. Melnik I.A. Intensities of superimposed epigenesis as an indicator of oil saturation in sandstone reservoirs. Bulletin of the Tomsk Polytechnic University. Geo Assets Engineering, 2019, vol. 330, no. 6, pp. 90-97.

16. Melnik I. A., Sharf I.V. Adding value to date when interpreting standard well logging measurements. Neftegazovoye delo, 2018, vol. 16, no. 3, pp. 11-21. In Rus.

17. Melnik I.A., Sharf I.V., Ivanova M.P. Statistical parameter of the double electric layer as an indicator of oil-saturation of the LowerMiddle Jurassic formation (Tomsk region). Neftyanoe hozyaistvo, 2018, no. 10, pp. 24-26. In Rus.

18. Melnik I.A. Opredelenie intensivnosti geokhimicheskikh protsessov po materialam geofizicheskikh issledovaniy skvazhin [Evaluating intensity of geochemical processes by well-logging data]. Novosibirsk, Siberian Research Institute of Geology, Geophysics and Minerals Publ., 2016. 146 p. 
19. Zanin Yu.N., Zamiraylova A.G., Eder V.G., Krasavchikov V.O Rare-earth elements in the Bazhenov formation of the WestSiberian sedimentary basin. Litosphere, 2011, no. 6, pp. 38-54. In Rus.
20. Surkov V.S., Zhero O.G. Fundament i razvitie chekhla ZapadnoSibirskoy plity [Base and development of West Siberian plate]. Modcow, Nedra Publ., 1981. 143 p.

Received: 12 September 2019.

\section{Information about the authors}

Igor A. Melnik, Dr. Sc., professor, National Research Tomsk Polytechnic University.

Natalya M. Nedolivko, Cand. Sc., associate professor, National Research Tomsk Polytechnic University.

Svetlana V. Zimina, Cand. Sc., associate professor, National Research Tomsk Polytechnic University. 